Research Article

\title{
Model Testing of Encased Stone Column Composite Foundations under Traffic Loads
}

\author{
Yongquan Yuan, Minghua Zhao $\mathbb{D}$, Yao Xiao, and Chaowei Yang \\ Institute of Geotechnical Engineering, Hunan University, Changsha 410082, China \\ Correspondence should be addressed to Minghua Zhao; mhzhaohd@21cn.com
}

Received 3 November 2020; Accepted 28 July 2021; Published 9 August 2021

Academic Editor: Guang-Liang Feng

Copyright (c) 2021 Yongquan Yuan et al. This is an open access article distributed under the Creative Commons Attribution License, which permits unrestricted use, distribution, and reproduction in any medium, provided the original work is properly cited.

\begin{abstract}
In soft soil foundations, geogrid encased stone column composite foundation technology has been widely applied and developed in recent years due to its efficient treatment. In this study, eight groups of laboratory model tests were performed in a large-scale testing tank to investigate the bearing mechanism and stress characteristics of the composite foundation of geogrid encased stone columns under traffic loads with different cyclic load ratios. The stress at the bottom of the stone column and settlement of the composite foundation were measured and analysed. The test results show that cyclic shearing will cause the rearrangement of the soil particles at the column-soil interface, which will cause changes in the face pressure and effective stress state of the column-soil boundary. The cyclic load has a substantial influence on the accumulation settlement of the composite foundation and the development of the lateral stress state of the column. Based on the test results, the development law of the cumulative settlement is summarized, and the change mechanism of the column stress state is analysed and discussed.
\end{abstract}

\section{Introduction}

In the modern civilized world, ground improvement techniques are of great importance for geotechnical engineers. Stone columns are effective, feasible, and economical for improving soft soils $[1-5]$. Stone columns installed in extremely soft soils may substantially reduce the effectiveness of this treatment due to the insufficient lateral confinement provided by the soft soil [6], so the encasement of columns with geotextiles is commonly used in these cases with satisfactory results because of the extra confinement provided by the geotextile to the column.

Van Impe [7] was the first to propose geosynthetic encasement to increase the bearing capacity of stone columns. The development of geosynthetic-encased stone columns has gained much progress in the last three decades. Four series of laboratory model tests were performed in a large-scale testing tank to investigate the effect of geogrid encasement on the lateral and vertical deformations of stone columns installed in a clay bed. In addition, the stress-strain characteristics of the encasement were measured and analysed by $\mathrm{Gu}$ et al. $[8,9]$. To provide the theoretical basis for the design and construction of an embankment with an encased stone column composite foundation, two groups of indoor model tests for the embankment with encased stone column composite foundation with different stiffnesses of the encasement were carried out in accordance with the influence of the stiffness of the encasement on the deformation and stability of the composite foundation with the encased stone column by Chen et al. [10]. The triaxial test of an encased stone column in a compact state was carried out by Chen et al. [11] to study the stress-strain characteristics of a column under different confining pressures and different strengths of polypropylene geotextile encasing materials. Yoo [12] presented the results of a numerical investigation on the settlement behaviour of embankments constructed on geosynthetic-encased stone columns installed in soft ground. Two-dimensional finite element analysis (FEA) was used to simulate the behaviour of a geosynthetic-encased stone column in soft clay loaded by an embankment. Parametric studies were then carried out by Almeida et al. [13] by varying the thickness of the soft soil layer and the 
tensile stiffness of the geosynthetic encasement for a given set of soft clay and column parameters.

The research topic is simplified as a plane strain problem, and then the dynamic response of stone column composite foundations under traffic loads is analysed by $\mathrm{Du}$ [14] by using linear elastic and elastoplastic soil constitutive relationships and the finite element method. Basack et al. [15] presented an analytical and numerical study on the behaviour of stone column stabilized soft ground supporting transport infrastructure. Analyses have been carried out on the response of reinforced soft ground under static and cyclic loading relevant to transport corridors.

As mentioned above, there are few studies on the bearing capacity of encased stone column composite foundations under dynamic loads. Therefore, it is important to study the dynamic stress characteristics of encased stone column composite foundations. In the present study, eight groups of laboratory model tests were performed in a large-scale testing tank to investigate the bearing mechanism and stress characteristics of the composite foundation of geogrid encased stone columns under traffic loads with different cyclic load ratios. The main objective of this research is to investigate the lateral stress of the stone column and the stress ratio between the stone column and soil. In addition, the stress at the bottom of the stone column and settlement of the composite foundation under cyclic loading were measured and analysed.

\section{Description of Experiment}

\subsection{Properties of the Materials}

2.1.1. Geogrid Encasement. A biaxial geogrid made of highdensity polyethylene (HDPE) was used for column reinforcement in this research. The strength and geometric properties of the geogrid are provided in Table 1. The encasement sleeve was prepared by cutting the HDPE and preparing it in a cylindrical shape with a latitudinal union with a diameter of $100 \mathrm{~mm}$. The length of the encasement sleeve was $400 \mathrm{~mm}$ in the model tests. Figure 1 is a photograph of the geogrid encasement.

2.1.2. Clay and Stone Column Materials. The clay soil was obtained from a lake bed of the Xiang River in Changsha city, China. The moisture content of the in situ soil ranged from $30 \%$ to $60 \%$ and its undrained shear strength was below $15 \mathrm{kPa}$. This soil can be classified as $\mathrm{CH}$ based on the USCS. Since the very soft soil was too soft for plate loading tests, an unconsolidated undrained (UU) triaxial test was conducted to estimate its undrained shear strength. Three groups of triaxial tests were carried out and the results were averaged. The soil samples for triaxial tests were obtained from the clay bed using a sampling tube with a diameter of $50 \mathrm{~mm}$ and a height of $100 \mathrm{~mm}$. The soil sample was extruded from the tube and trimmed into a desired size (i.e., $38 \mathrm{~mm}$ in diameter and $76 \mathrm{~mm}$ in height) with great care to reduce the degree of disturbance. The detailed properties of the clay soils are listed in Table 2.
TABle 1: Properties of the biaxial geogrid.

\begin{tabular}{lc}
\hline Parameters & Value \\
\hline Tensile strength at an elongation of 2\% & $17.6 \mathrm{kN} / \mathrm{m}$ \\
Tensile strength at an elongation of 5\% & $23.7 \mathrm{kN} / \mathrm{m}$ \\
Width of the rib & $4 \mathrm{~mm}$ \\
Mesh aperture size & $8 \mathrm{~mm} \times 8 \mathrm{~mm}$ \\
\hline
\end{tabular}

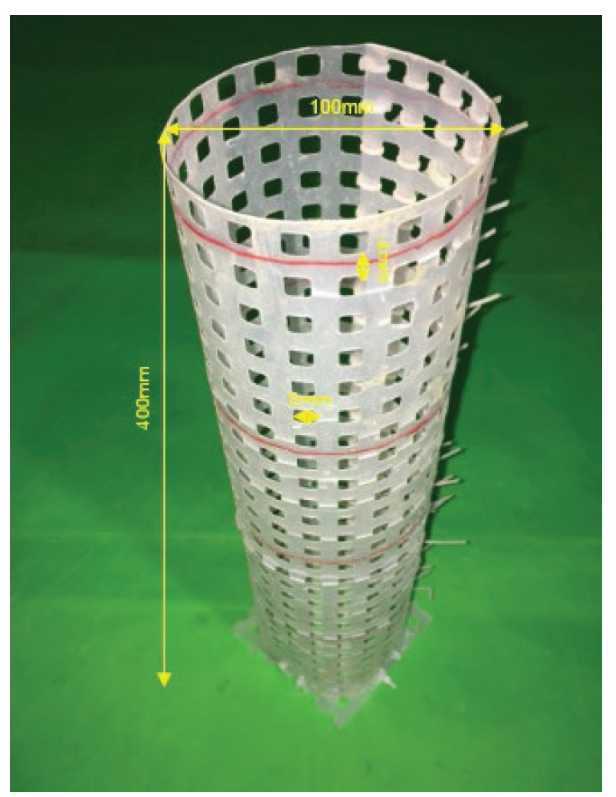

FIgURE 1: Typical photograph of the geogrid encasement.

TABle 2: Properties of the clay soils.

\begin{tabular}{lc}
\hline Parameters & Value \\
\hline Liquid limit & $64.6 \%$ \\
Plastic limit & $35.2 \%$ \\
Plastic index & $29.4 \%$ \\
Specific gravity & 2.55 \\
Moisture content of the clay & $42.5 \%$ \\
Undrained shear strength of the clay & $4.7 \mathrm{kPa}$ \\
USCS symbol & $\mathrm{CH}$ \\
\hline
\end{tabular}

Figure 2 shows the particle size distribution for the stone columns, and Table 3 describes the properties of the stone material.

2.2. Preparation of the Experimental Model. The sizes of the model tests were designed at a scale ratio of $1 / 5$ of those of typical field tests. A large test tank with a length of $2.2 \mathrm{~m}$, a width of $1.8 \mathrm{~m}$, and a depth of $1.2 \mathrm{~m}$ was used. To reduce the boundary friction, the inner periphery of the test tank was covered with $20 \mathrm{~mm}$ thick foam boards and plastic sheets.

A replacement method was adopted for the installation of the stone columns. After levelling the top surface of the clay bed, the stone column was cast in steps. To construct an encased column, four PC pipes with an outer diameter equal to the required diameter of the stone column were first placed in the tank at the required level. The whole column 


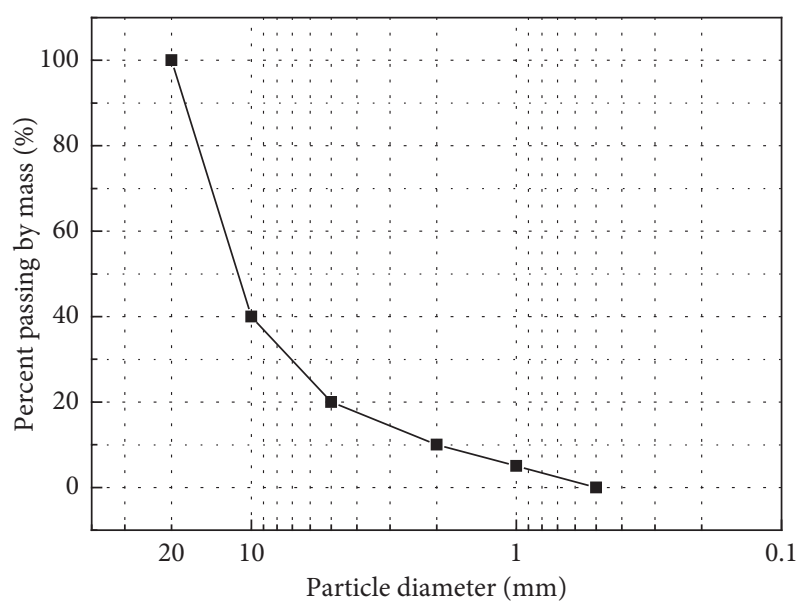

FIgURE 2: Stone particle size distribution.

TABle 3: Properties of aggregates.

\begin{tabular}{lc}
\hline Parameters & Value \\
\hline Size range & 0.5 to $20 \mathrm{~mm}$ \\
$D_{10}, D_{30}$, and $D_{60}$ & 2,7, and $15 \mathrm{~mm}$ \\
Peak friction angle & $43.23^{\circ}$ \\
Specific gravity & 1.6 \\
Dry density & $2.52 \mathrm{~g} / \mathrm{cm}^{3}$ \\
Relative density & $67 \%$ \\
USCS symbol & $\mathrm{GP}$ \\
\hline
\end{tabular}

length was first divided into several equal parts, each equal in size to 2 times the column diameter. The quantity of stones needed to construct each of these parts at a relative density of $67 \%$ was then weighed and kept separately in a tray. After the stones for the first part were filled into the pipe, the stones were uniformly compacted using a $12 \mathrm{~mm}$ diameter steel rod. The stones for the second layer were then filled and compacted in the same manner. This process was continued until the full column length was constructed. This ensured that the columns were cast with a constant density. The clay bed was formed around the pipes. The soil had been consolidated before being filled. The clay soil was filled in layers of $200 \mathrm{~mm}$ each time. After the placement of each layer, a miniature cone penetrometer was used to evaluate the uniformity of the layer. The moisture contents of the soil were measured at eight different locations inside the test tank and the variation of the measured moisture contents was controlled within $1 \%$ difference. When the clay soil and stone were filled to a height of $600 \mathrm{~mm}$ from the tank bottom, the encasement sleeves were assigned outer to the PC pipes. The diameter of the stone columns was $100 \mathrm{~mm}$, corresponding to a field column size of $500 \mathrm{~mm}$. The geogrid used in this study was a biaxial geogrid, which is also commonly used in the field. Biaxial geogrids have many varieties with a wide range of strengths, typically from $20 \mathrm{kN} / \mathrm{m}$ to $200 \mathrm{kN} / \mathrm{m}$. The geogrid used in this study is one of the weakest ones. By considering the scale effect, the strength of the geogrid is still within the typical range; and the sensors were assigned along with the model forming.
Then, the clay soil with the column inside was covered with wet jute fabric in controlled conditions for $24 \mathrm{~h}$ to develop proper bonding between the stones of the column and the clay soil. The preparation of the model is shown in Figure 3.

2.3. Load Tests. Plate loading tests were conducted on a single column and composite foundation consisting of one column and its surrounding soil in this study, as shown in Figure 4. Also the positions of sensors were shown in Figure 4. Figure 5 shows the plate load test setup. In the model test, only the vertical loading part was considered. To simulate the characteristics of traffic loads, a continuous half-sine loading curve was used as the dynamic loading curve, as shown in Figure 6. In this test, the loading frequency of the dynamic load was approximately $3 \mathrm{~Hz}$, and the corresponding data sampling frequency was set to $50 \mathrm{~Hz}$. N is the number of cycles. The single-stage dynamic loading can be terminated if one of the following two standards is met: (1) the single-stage cumulative settlement reaches $0.1 d$ ( $d$ is the diameter of a single column); (2) the number of single cycles is 50,000 times.

Eight groups of plate loading tests were conducted by varying the cyclic load ratio. Four encased stone columns (labelled A1, B1, C1, and D1) were installed in the clay bed for each series of tests in the tank, as shown in Figure 4. These columns were loaded to simulate single stone columns with a loading plate of $100 \mathrm{~mm}$ in diameter. The other four encased columns (labelled A2, B2, C2, and D2) were installed in the clay bed for each series of tests in the tank, as shown in Figure 4. These columns were included in the composite foundations loaded with a loading plate with diameter of $250 \mathrm{~mm}$. Table 4 summarizes the program of the plate load tests conducted on the stone columns.

\section{Results and Discussion}

3.1. Settlement at the Top of a Single Column and Single Column Composite Foundation. Under vertical cyclic loading, the soil at the bottom of the model bears the cyclic compressive stress, and the column-soil interface at the column side bears the repeated shear action. The accumulative settlement of the model top is the macroscopic embodiment of this rearrangement. Figures 7(a) and 7(b) show the development of the model top cumulative settlement with the number of cycles. It can be seen from the figures that there are obvious differences in the development rules of the cumulative settlement under the action of different CLRs (cyclic load ratios), where CLR $=P_{\mathrm{c}} / P_{\mathrm{u}}\left(P_{\mathrm{c}}\right.$ is cyclic load amplitude and $P_{\mathrm{u}}$ is vertical ultimate bearing capacity of a single column). However, when the CLR is less than 0.2, cumulative settlement rarely occurs; that is, there is a minimum cyclic load ratio (MCLR).

As shown in Figure 7(b), when the CLR is equal to 0.2, the composite foundation becomes stable after minimal cumulative settlement occurs in the first 10 cycles, no cumulative settlement occurs in the loading course, and the cyclic load ratio is the MCLR. As shown in Figure 7(b), when 

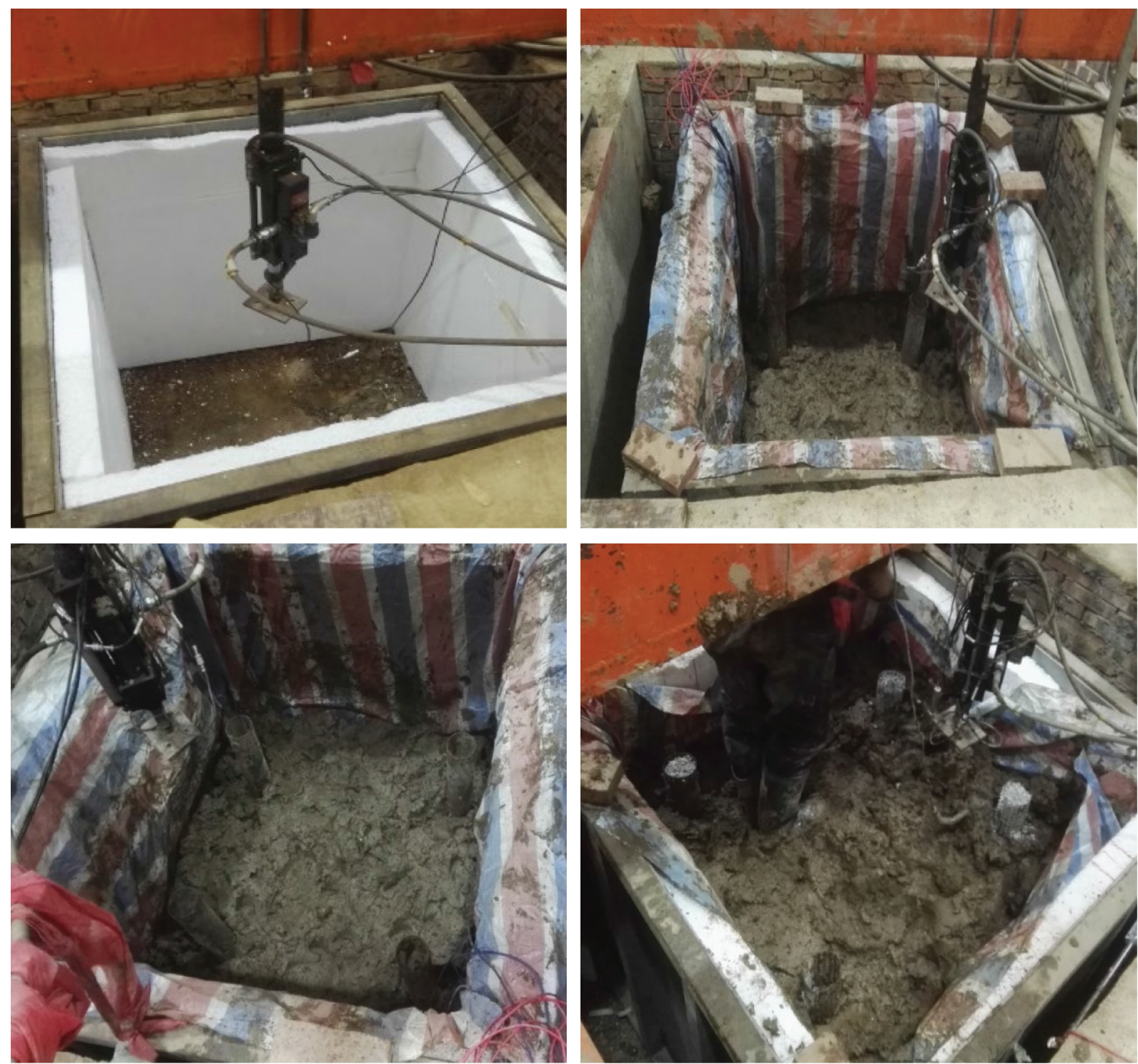

FIGURE 3: The preparation of the model.

CLR $\geq 0.4$, the top settlement of the model develops rapidly, and the magnitude value is large. Especially under the load of the last stage, the composite foundation is rapidly destroyed within thousands of cycles, and the cumulative settlement reaches $0.1 d$ ( $d$ is the diameter of a single column). The cyclic load ratio is the FCLR (failure cyclic load ratio). When the cyclic load ratio is between 0.4 and 0.5 , the settlement gradually accumulates with the number of cycles. The settlement accumulation speed in the initial cycle is fast and then decreases gradually. The settlement amount corresponding to the accumulation rate and a certain number of cycles is proportional to the CLR. Therefore, when CLR $\leq$ MCLR, the cumulative settlement develops into a nondevelopmental type. When MCLR $<$ CLR $<$ FCLR, the cumulative settlement develops into the developmental type. When CLR $\geq$ FCLR, the cumulative settlement develops into the destructive type.
As shown in Figure 7(a), the failure cumulative settlement is almost $16 \mathrm{~mm}$, and the destroyed number of cycles is less than 30,000. However, the destroyed cumulative settlement is almost $12.5 \mathrm{~mm}$, and the destroyed number of cycles is more than 30,000 in Figure 7(b). It can be concluded from the figures that the surrounding soils of the column in the single column composite foundation bear part of the cyclic load.

\subsection{Compressive Stress at the Column Bottom.}

Figures 8(a) and 8(b) show the typical column bottom resistance curve under dynamic loading. It can be seen from Figures 8(a) and 8(b) that, in the initial stage of loading, the column bottom resistance increases with the increase in the number of loading cycles, and it experiences the passing down of the load at the column top. When the loading cycle 


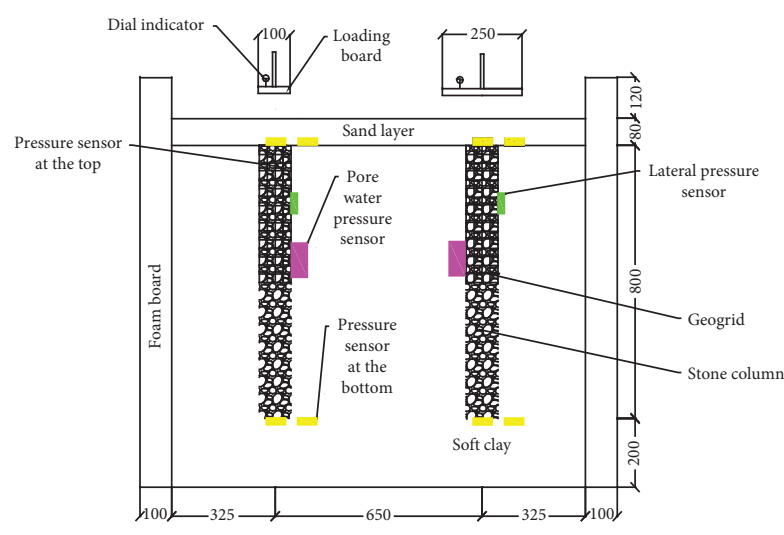

(a)

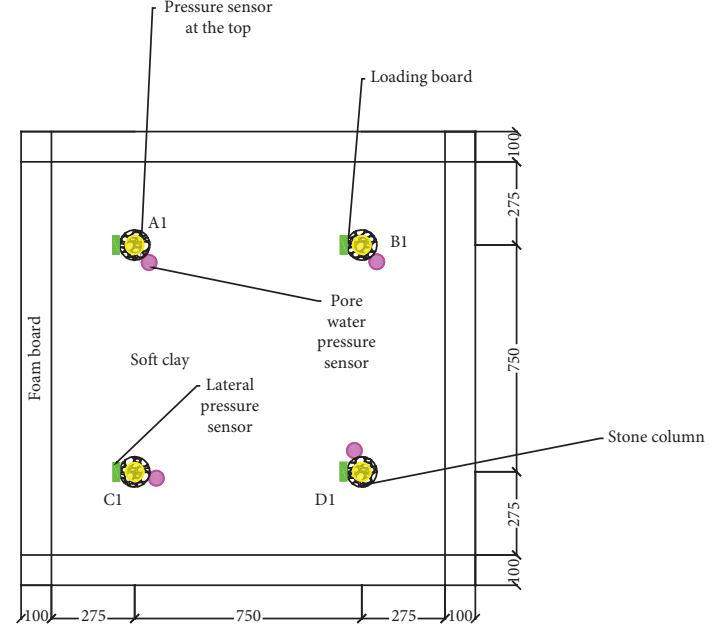

(b)

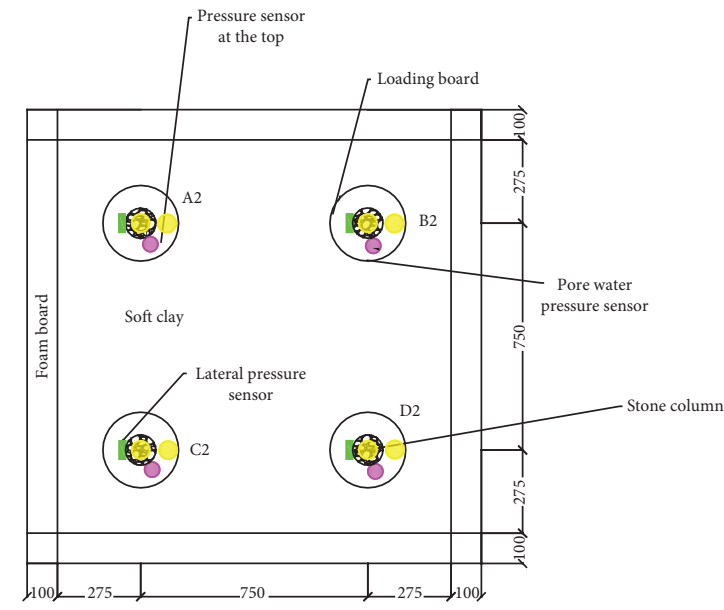

(c)

Figure 4: Load tests on the models. (a) Single column, (b) plan view of a single column, and (c) plan view of a single column composite foundation.

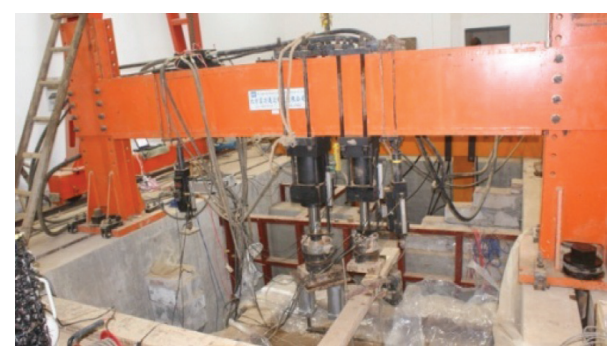

FiguRE 5: Testing setup.

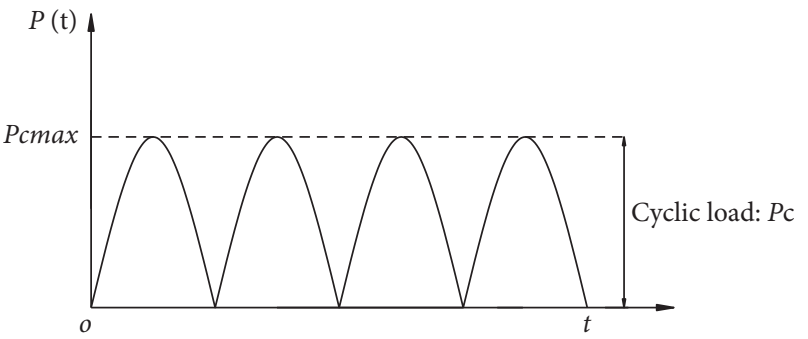

Figure 6: Dynamic loading curve. 
TABLE 4: Plate loading tests on the composite foundations.

\begin{tabular}{|c|c|c|c|c|}
\hline Test type & Experimental label & Encased length of column (mm) & Cyclic load ratio & Total number of the test \\
\hline \multirow{4}{*}{ Single column } & A1 & 400 & 0.2 & 2 \\
\hline & B1 & 400 & 0.3 & 2 \\
\hline & $\mathrm{C} 1$ & 400 & 0.4 & 2 \\
\hline & D1 & 400 & 0.5 & 2 \\
\hline \multirow{4}{*}{ Composite foundation with a column } & A2 & 400 & 0.2 & 2 \\
\hline & B2 & 400 & 0.3 & 2 \\
\hline & $\mathrm{C} 2$ & 400 & 0.4 & 2 \\
\hline & D2 & 400 & 0.5 & 2 \\
\hline
\end{tabular}

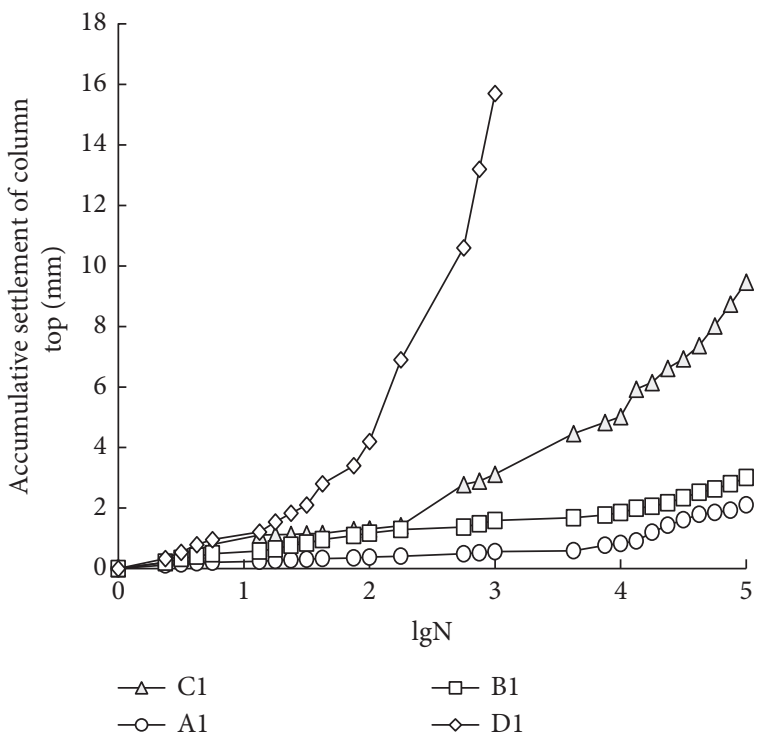

(a)

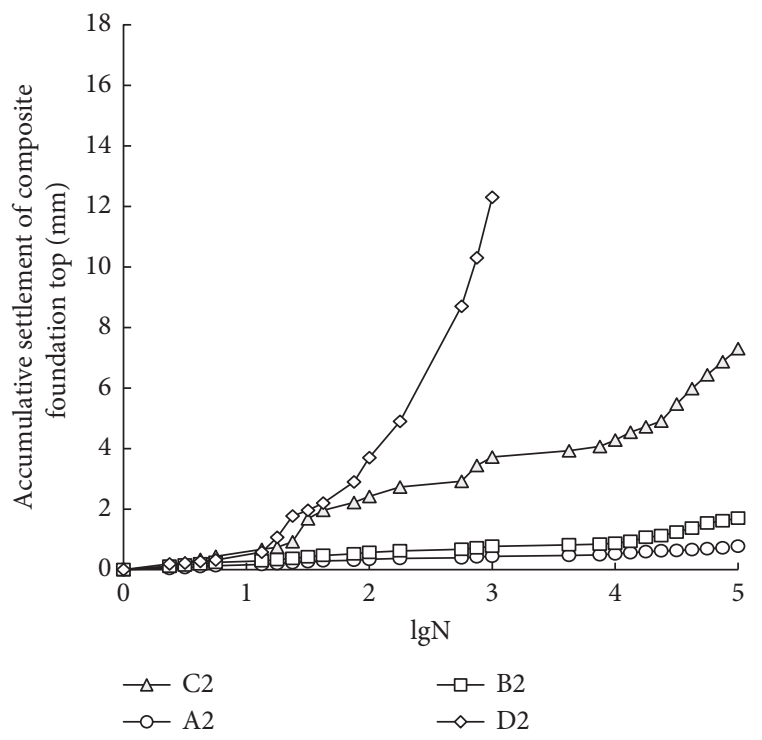

(b)

FIgURE 7: Settlement at the top: (a) single column; (b) single column composite foundation.

reaches approximately 10 , the column bottom resistance no longer increases obviously and then presents a cycle change tendency along with the cyclic load. It can be concluded that cyclic loading leads to the compression of the stone column, and the soil particles at the column bottom are densely arranged. Therefore, the resistance development of the column bottom is an obvious hardening type.

As shown in Figure 8(a), the maximum compressive stress at the column bottom of D1 is almost $85 \mathrm{kPa}$. However, the maximum compressive stress at the column bottom of D2 is almost $62 \mathrm{kPa}$ in Figure $8(\mathrm{~b})$. It can be concluded from the figures that the surrounding soils of the column in the single column composite foundation bear part of the cyclic load.

\subsection{Lateral Compressive Stress of the Stone Column}

3.3.1. Lateral Excess Pore Water Pressure of the Column. Figures 9(a) and 9(b) show the development of pore water pressure at the column-soil interface with the change in the number of cycles in typical dynamic loading tests. It can be clearly seen from Figures 9(a) and 9(b) that when the model is under cyclic shearing, the pressure of the boundary face increases rapidly in the initial cycle, gradually decreases, and becomes stable after reaching the peak. The boundary pressure fluctuation shows that the pore volume of saturated soil has changed, so the monitored boundary pressure change is an intuitive manifestation of the rearrangement of the soil particles at the column-soil interface under cyclic shear action. The initial increase in the pore pressure indicates that cyclic shear will cause the soil particles at the column-soil interface to be more closely arranged, and the pore volume between the soil particles will be smaller, thus resulting in an increase in the pore pressure. Due to the fine permeability of the soil, the accumulated pore pressure gradually dissipates after reaching the peak. After a certain cycle period, the rearrangement of the soil particles at the column-soil interface was completed and stabilized, and the interface reaction under repeated shear action was close to elastic; that is, there was no plastic volume strain, and the pore pressure fluctuated periodically with the number of cycles. The peak pore pressure at the initial stage is proportional to the CLR, indicating that the interfacial soil particle rearrangement is more intense under the action of the larger CLR. At the same time, it is noted that the number of cycles when the pore pressure reaches the peak is basically within 10 cycles, indicating that the interface reaction is the 


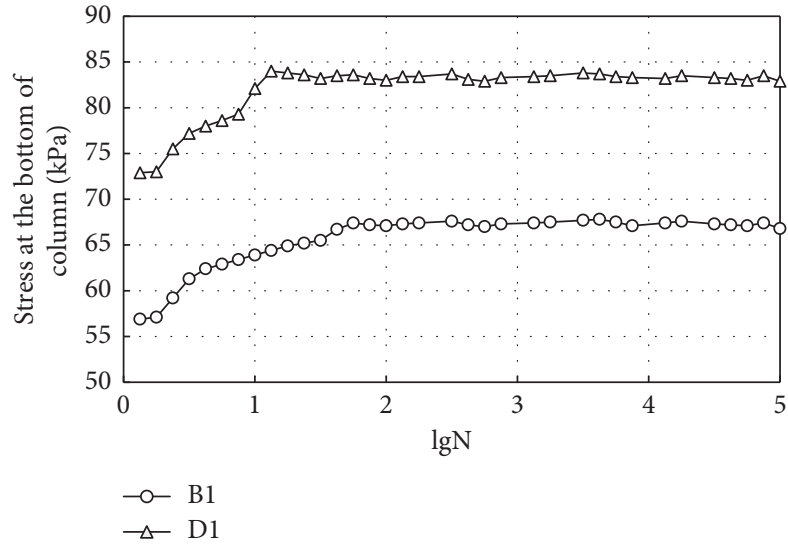

(a)

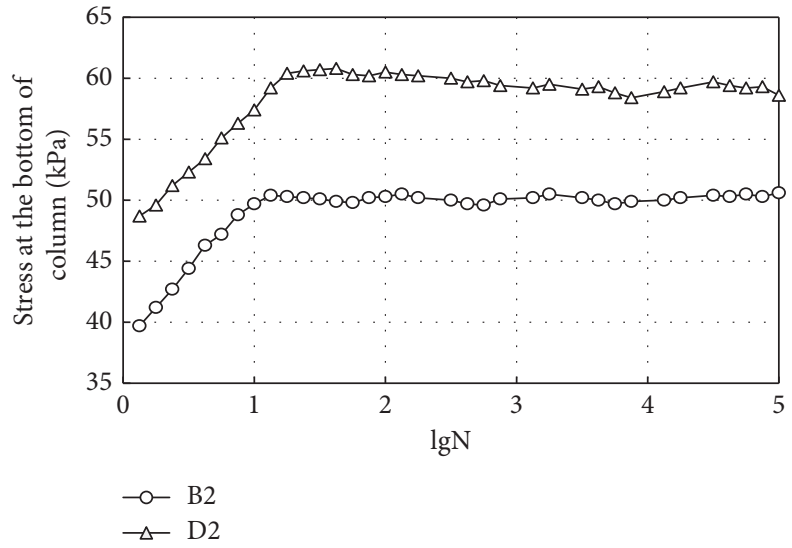

(b)

Figure 8: Compressive stress at the column bottom: (a) single column; (b) single column composite foundation.

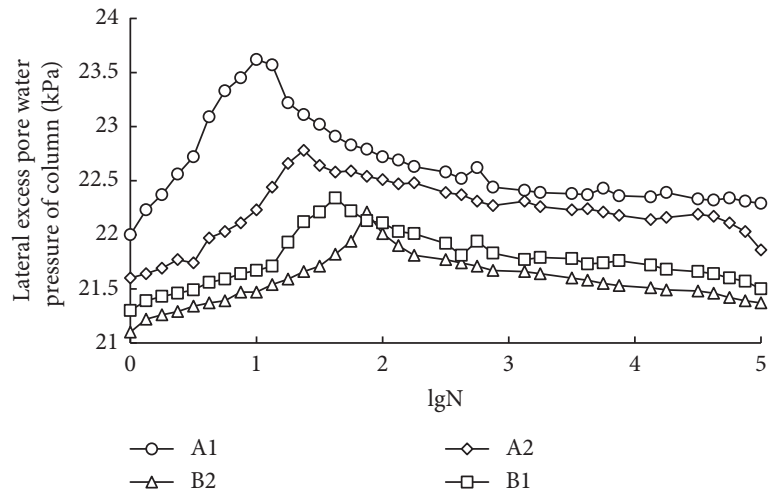

(a)

FIGURE 9: Lateral superpore water pressure of the column:

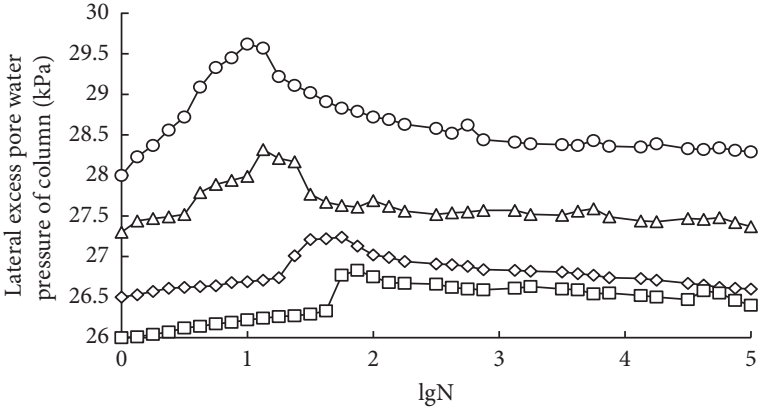

$\begin{array}{ll}\multimap \mathrm{C} 1 & \multimap \mathrm{D} 1 \\ \neg \mathrm{C} 2 & \rightarrow-\mathrm{D} 2\end{array}$

(b)

(a) $\mathrm{CLR}=0.2$ and $\mathrm{CLR}=0.3$; (b) $\mathrm{CLR}=0.4$ and $\mathrm{CLR}=0.5$.

strongest in the initial loading phase. In addition, Figures 9(a) and 9(b) show that, even under the action of a minimum CLR, certain particle rearrangements and volume changes will still occur at the column-soil interface.

3.3.2. Lateral Total Compressive Stress of the Column. Figures 10(a) and 10(b) show the development of the total stress of the column-soil interface with the change in the number of cycles in a typical dynamic loading test. The development of the total interfacial stress is the overall performance of the development of the pore pressure and soil pressure, which is affected by many factors. As seen from Figures 10(a) and 10(b), during the initial stage of cyclic shearing, the total stress increases rapidly and reaches the peak, then decreases rapidly and gradually, and then recovers and stabilizes after reaching the valley value. In the initial stage, the rapid rise of the boundary pressure is the main factor that leads to the increase in total stress. Then, the radial effective stress is reduced due to pore pressure dissipation and cyclic shearing shrinkage, and the total stress is gradually reduced. After the total stress decreases to the valley value, the value recovers with the increase in the number of cycles. When the CLR is small, the effective stress reduction of the interface caused by the circulation is small, so the subsequent stress recovery is more obvious than when the CLR is large. When the number of cycles is large, usually after tens of thousands of cycles, the interface reaction is close to being elastic, and the total stress finally reaches a stable value. The CLR has a substantial influence on the range of the peak and valley values in the process of total stress development: a larger CLR will lead to a more obvious range of the rise and fall in the process of total stress development.

3.3.3. Lateral Effective Compressive Stress of the Column. According to the monitoring results of the boundary pressure and total stress, the development law of the effective stress at the column-soil interface with the change in the number of cycles can be obtained, as shown in Figures 11(a) and 11(b). As seen from Figures 11(a) and 11(b), the development law of the effective stress at the interface is similar to the development law of the total stress. However, since the development of the total stress involves the change in the pore pressure, the variation amplitudes of the two are quite 


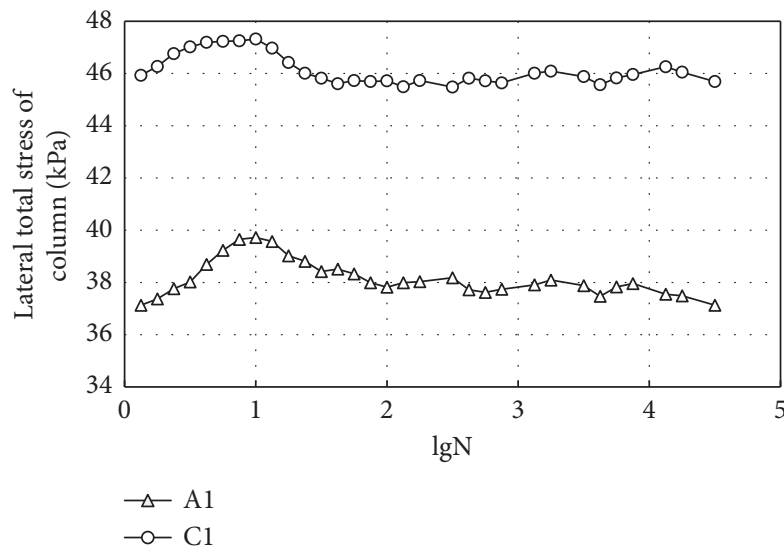

(a)

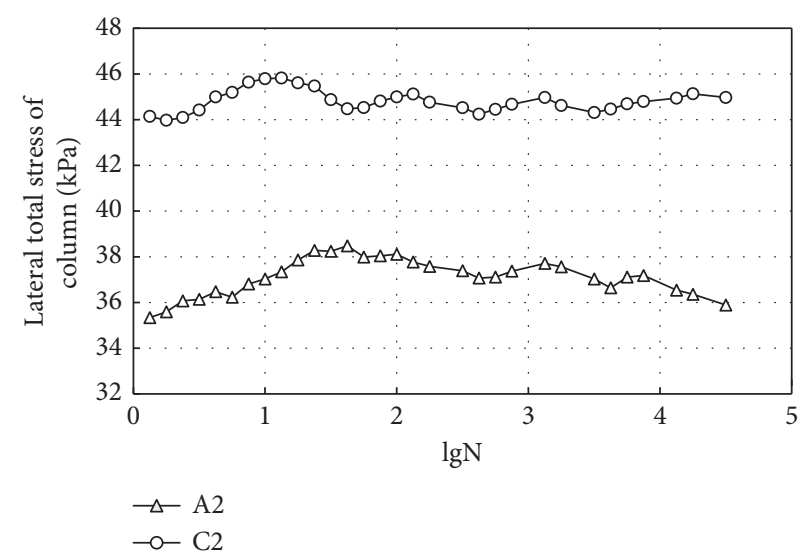

(b)

FIGURE 10: Lateral total stress of the column: (a) single column; (b) single column composite foundation.

different. In dynamic loading, the effective stress of the column-soil interface decreases rapidly and then recovers and stabilizes. Figures 9 and 11 show that the cyclic shear action at the initial stage will cause shear shrinkage of the interface soil. On the one hand, clipping causes the pressure of the boundary face to rise, and, on the other hand, a substantial reduction in the effective stress occurs. Under the action of different CLRs, the development of the effective stress is obviously different, and the weakening amplitude of the effective stress on the column side is proportional to the CLR. When the CLR is small, the effective stress decreases less, and, after a certain number of cycles, it can basically be restored to the precycle level. When the CLR is large, the effective stress decreases substantially, and the recovery value after a certain number of cycles also decreases substantially compared with that before the cycle. The reduction in the effective stress at the interface leads to the weakening of the column lateral confinement, which explains the redistribution of the column axial force caused by dynamic loading.

As shown in Figure 11(a), the maximum lateral effective stress of column A1 is almost $16.5 \mathrm{kPa}$. However, the maximum lateral effective stress of column A2 is almost $15.7 \mathrm{kPa}$ in Figure 11(b). It can be concluded from the figures that the surrounding soils of the column in the single column composite foundation bear part of the cyclic load.

3.4. Stress Ratio between the Stone Column and Soil. It can be seen from Figures 12(a) and 12(b) that the column-soil stress ratio under cyclic loading decreases with the increase in the number of loading times. When the number of loading times is small, the column-soil stress ratio decreases rapidly. When the number of cycles increases to a certain degree, the basic stress ratio of the column-soil remained stable, indicating that, at the beginning of the load, the stress is mainly concentrated on the column, the stress with the increase in the number of cycles is shifted from the column to soil between columns, and the column stress increases with the number of cycles, thus causing the column-soil stress ratio to decrease with the increase in the number of cycles. In addition, Figures 12(a) and 12(b) show that the column-soil stress ratio is also affected by the cyclic stress ratio. If the cyclic stress ratio is large, the column-soil stress ratio is large.

\section{Comparison with the Model under Static Loading}

To investigate the differences between the dynamic characteristics and static characteristics of the models, the model test under static loading is compared with the model test under cyclic loading.

4.1. Stress Ratio between the Stone Column and Soil. Figure 13 shows that the stress ratio increases continually with increasing test time. This means that the bearing capacity of the stone column develops gradually and particles of the surrounding soils are denser when the model is under static loading. However, the stress ratio increases rapidly at the early stage when the model is under cyclic loading. While the stress ratio reaches a certain value, it exhibits a period changing trend.

4.2. Lateral Compressive Stress of the Column. Figure 14 shows that the load is continually transmitted to the depth with the increment of the test time, so the confining pressure of the surrounding soils increases. This leads to the extension of the lateral compressive stress of the column when the model is under static loading. However, the lateral compressive stress of the column increases rapidly at the early stage when the model is under cyclic loading. While the lateral compressive stress of the column reaches a certain value, it exhibits a period changing trend. 


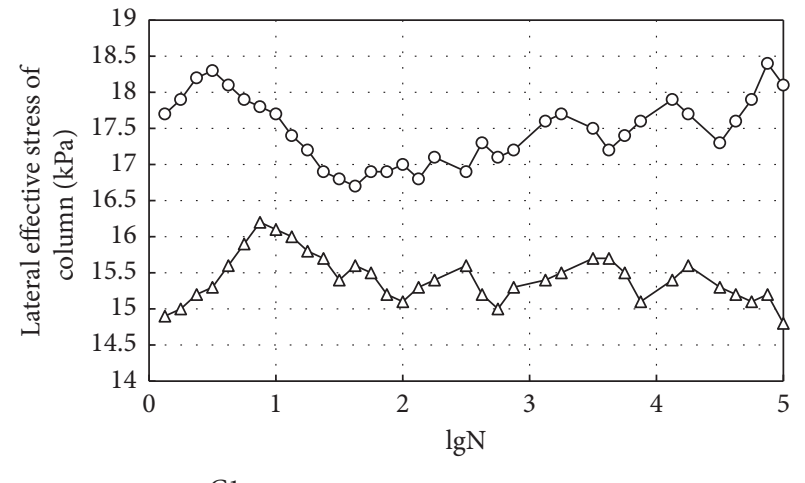

$\rightarrow \mathrm{C} 1$
$\rightarrow \mathrm{A} 1$

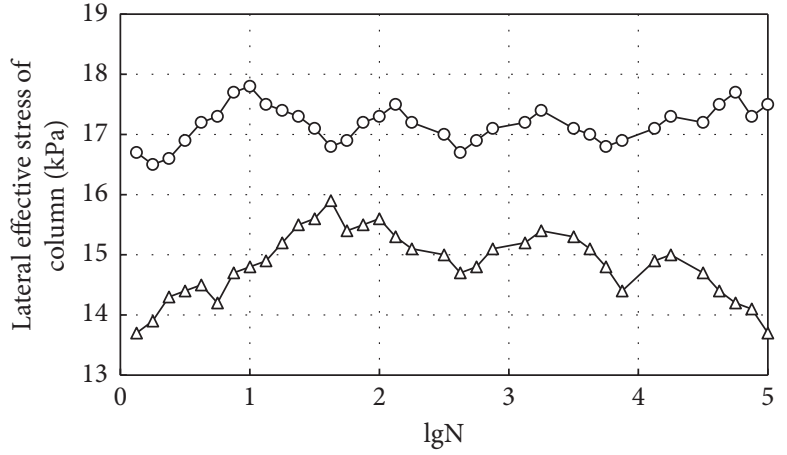

$\multimap \mathrm{C} 2$

(a)

(b)

FIgURE 11: Lateral effective stress of the column: (a) single column; (b) single column composite foundation.

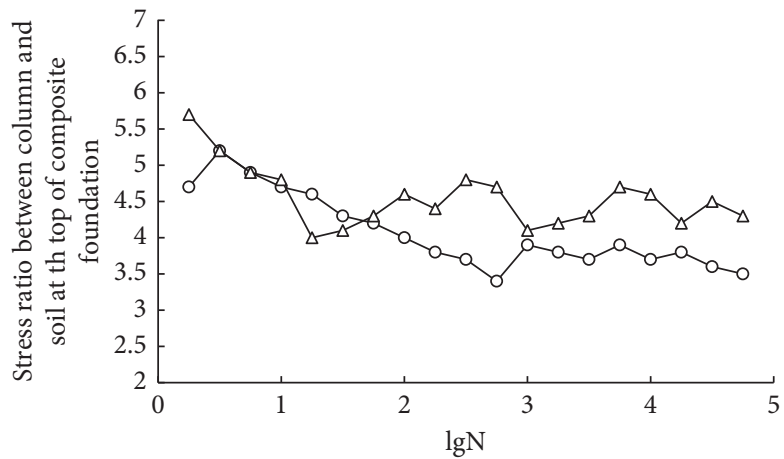

$\rightarrow$ A2

$\rightarrow-\mathrm{C} 2$

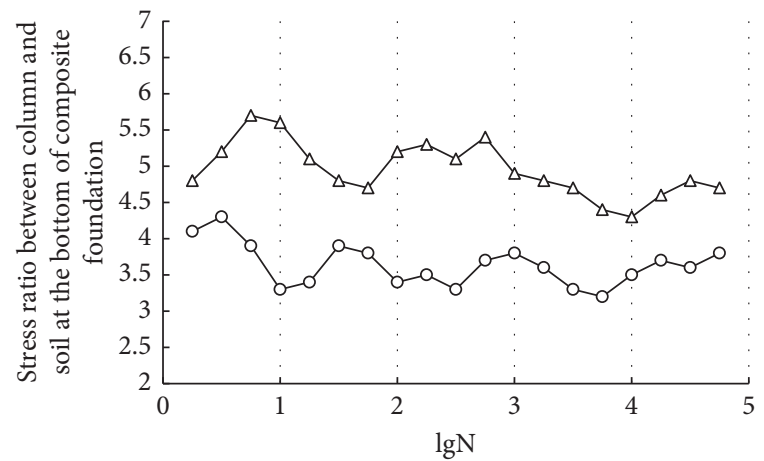

$\rightarrow$ B2

$\rightarrow \mathrm{D} 2$

(a)

(b)

Figure 12: Stress ratio between the stone column and soil: (a) CLR $=0.2$ and CLR $=0.4$; (b) $C L R=0.3$ and CLR $=0.5$.

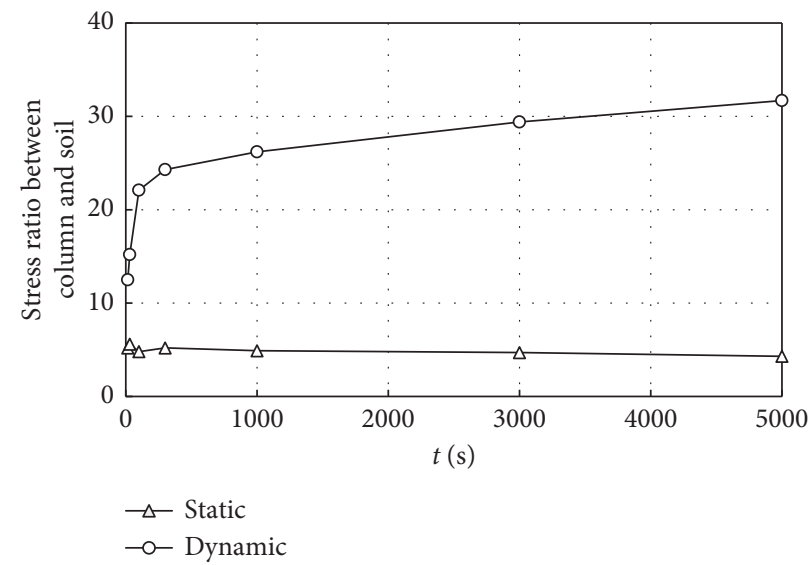

FIGURE 13: Stress ratio between the stone column and soil. 


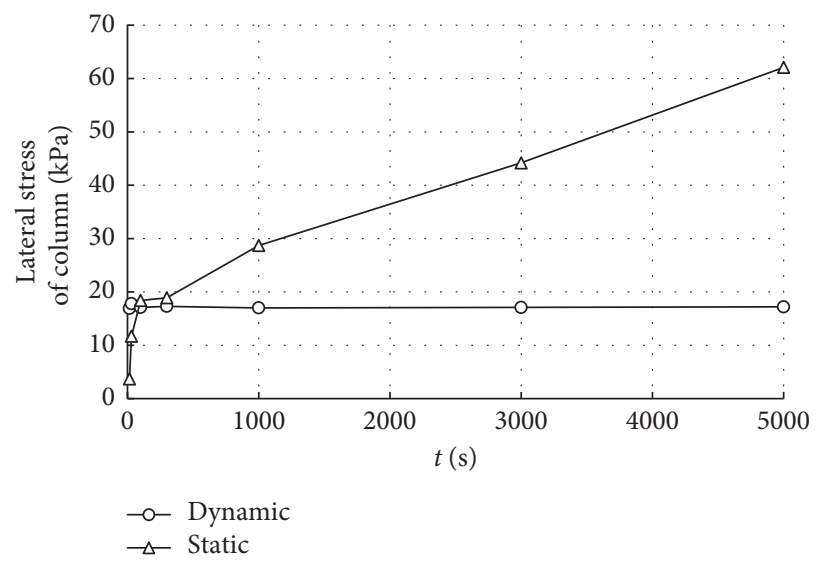

Figure 14: Lateral stress of the stone column.

\section{Conclusions}

In this study, laboratory model tests were performed on geogrid encased stone columns and geogrid encased stone column composite foundations to investigate the settlement and stress characteristics of single column and single column composite foundations under cyclic loading. The following conclusions were drawn:

(1) There are obvious differences in the development rules of the cumulative settlement under the action of different CLRs. However, when the CLR is less than 0.2 , the cumulative settlement almost never occurs; that is, there is a MCLR.

(2) The cyclic load leads to the compression of the stone column, and the soil particles at the column bottom are densely arranged. Therefore, the resistance development of the column bottom is an obvious hardening type.

(3) The load is continually transmitted to the depth with the increment of the test time, so the confining pressure of the surrounding soils increases. This leads to the enhancement of the lateral compressive stress of the column when the model is under static loading. However, the lateral compressive stress of the column increases rapidly at the early stage and then exhibits a period changing trend when the model is under cyclic loading. A larger CLR will lead to a more obvious rising and falling range in the process of total stress development.

(4) The stress ratio between the stone column and soil increases continually with increasing test time when the model is under static loading. However, the column exhibits a period changing trend when the model is under cyclic loading.

\section{Data Availability}

The case analysis data used to support the findings of this study are available from the corresponding author upon request.

\section{Conflicts of Interest}

The authors declare that there are no conflicts of interest regarding the publication of this paper.

\section{Acknowledgments}

This research was funded by the National Natural Science Foundation of China (NSFC) (no. 51478178).

\section{References}

[1] S. S. Rani and P. S. P. Kumar, "A study of behaviour on stone column in homogenous soil," International Journal of Science and Research, vol. 5, pp. 1215-1219, 2015.

[2] J. Gniel and A. Bouazza, "Improvement of soft soils using geogrid encased stone columns," Geotextiles and Geomembranes, vol. 27, no. 3, pp. 167-175, 2009.

[3] K. Liu, J. Xu, and L. Cao, "Numerical analysis of bearing characteristics of steel flexible pile rein forced cushion composite foundation," Journal of Zhejiang University of Science and Technology (Natural Science Edition), vol. 39, no. 3, pp. 372-377, 2018.

[4] A. Tognon, R. K. Rowe, and R. W. I. Brachmen, "Evaluation of side wall friction for a buried pipe testing facility," Geotextiles and Geomembranes, vol. 17, no. 4, pp. 193-212, 1999.

[5] M. Zhao, W. He, and S. Heng, "Research on the calculation method of bearing capacity of reinforced hoop gravel pile based on the theory of circular hole expansion," Chinese Journal of Geotechnical Engineering, vol. 39, no. 10, pp. 1785-1792, 2017.

[6] M. Miranda and A. Da Costa, "Laboratory analysis of encased stone columns," Geotextiles and Geomembranes, vol. 44, no. 3, pp. 269-277, 2016.

[7] W. F. Van Impe, Soil Improvement Techniques and Their Evolution, pp. 63-66, Balkema, Rotterdam, The Netherlands, 1989.

[8] M. Gu, M. Zhao, L. Zhang, and J. Han, "Effects of geogrid encasement on lateral and vertical deformations of stone columns in model tests," Geosynthetics International, vol. 23, no. 2, pp. 100-112, 2016.

[9] M. Zhao, M. Gu, and L. Zhang, "Model test study on the influence of vertical geotechnical reinforced body on bearing 
deformation of gravel pile," Chinese Journal of Geotechnical Engineering, vol. 36, no. 9, pp. 1587-1593, 2014.

[10] J. Chen, B. Wang, and J. Wei, "Model test of reinforced gravel pile composite foundation embankment," Chinese journal of highways and highways, vol. 28, no. 9, pp. 1-8, 2015.

[11] J. Chen, X. Wang, and Y. Zeng, "Experimental study on the triaxial test of geotextile scattered piles," Chinese Journal of Geotechnical Engineering, vol. 39, no. 12, pp. 2212-2218, 2017.

[12] C. Yoo, "Settlement behavior of embankment on geosynthetic-encased stone column installed soft ground-a numerical investigation," Geotextiles and Geomembranes, vol. 43, no. 6, pp. 484-492, 2015.

[13] M. S. S. Almeida, I. Hosseinpour, and M. Riccio, "Performance of a geosynthetic-encased column (GEC) in soft ground: numerical and analytical studies," Geosynthetics International, vol. 20, no. 4, pp. 252-262, 2013.

[14] P. Du, "Research on dynamic characteristics of gravel pile composite foundation under traffic load," Master's thesis, Beijing Jiaotong University, Beijing, China, 2012.

[15] S. Basack, B. Indraratna, and C. Rujikiatkamjorn, "Analysis of the behaviour of stone column stabilized soft ground supporting transport infrastructure," Procedia Engineering, vol. 143, pp. 347-354, 2016. 